\title{
Em casa com o antisemitismo: paisagens domésticas vienenses do fin-de-siècle
}

\begin{abstract}
This article takes a new look at the novels of the Austrian Jewish writer Adolf Dessauer (1849-1916). Dessauer wrote an ironic chronicle of his contemporaries' world in turn-of-the-century Vienna. A banker by profession and an amateur novelist, he published two novels in his lifetime (Götzendienst, in 1896, and Großstadtjuden, in 1910), both taking place in the Habsburg capital, which was then undergoing a process of rapid economic and social change. Though his books are nowadays virtually forgotten, Dessauer was a very accurate chronicler of the customs of the social class which ascended with economic liberalism, and which became increasingly close to the empire's declining aristocracy, mimicking its tastes and habits.
\end{abstract}

As opposed to what happened in other European nations, the bourgeoisie in the Habsburg Empire never attempted to construct its own aesthetic and cultural repertoire, but consistently imitated the aristocratic patterns of its time. Dessauer makes a biting and ironical portrait of this class and its attempt at aristocratic appearances.

He also shows how Karl Lueger's Christian anti-Semitic party in Austria recruited its voters from the impoverished class of artisans, which had lost space as a consequence of the establishment of a new economic order. Lueger's

\footnotetext{
${ }^{*} \mathrm{O}$ autor é doutorando no programa de Literatura e Cultura judaica da USP.
} 
political campaign was directed towards this growing class, and he identified the rise of liberal capitalism with Jews and Judaism.

In Großstadtjuden Dessauer looks at the same phenomena, but does so from a strictly Jewish point of view. His second novel portrays the reactions of a number of Jewish families from Vienna to rising anti-Semitism. This historical aspect of the Viennese Jewish community, which was Europe's numerically largest after Warsaw's, is a striking prelude to the history of European Jewry in the 20th.century, thus giving Dessauer's work an unexpected afterlife.

Keywords: Habsburg monarchy; Austro-Jewish symbiosis; Assimilation; AntiSemitism; Jewish emancipation.

Zusammenfassung: Dieser Artikel behandelt den österreichischen Autor Adolf Dessauer (1849-1916), einen Chronisten der Wiener Sitten de Wende vom 19. zum 20. Jahrhundert. Von Beruf Bankier und Schriftsteller aus Liebhaberei, veröffentlichte Dessauer zwei Romane (Götzendienst, 1896 und Großstadtjuden, 1910), die zu Zeiten rasanter wirtschaftlicher und sozialer Wandlungen in der Habsburger Metropole spielen und die heute nahezu vergessen sind. Dessauer richtet seine Aufmerksamkeit auf die Klasse, die mit dem Siegeszug des Wirtschaftsliberalismus aufgestiegen und sich immer mehr mit der dekadenten Aristokratie der österreichischen Hauptstadt verbunden hatte, deren Geschmack und Umgangsformen sie nachahmte. Im Unterschied zu anderen europäischen Nationen schuf das Bürgertum des Habsburger Reiches kein eigenständiges kulturelles oder ästhetisches Repertoire, sondern versuchte, sich auf dem Wege der Imitation die kulturellen Werte des Adels anzueignen, was eine Klasse von Nachahmern hervorrief, auf die Dessauer seinen durchdringenden und ironischen Blick richtete.

Gleichzeitig zeigt Dessauer, wie die Partei der antisemitischen Christdemokraten in Österreich unter der Schicht der Handwerker ihre Wähler rekrutierte, die im Zuge der neuen wirtschaftlichen Ordnung proletarisiert wurden: An diese verarmten Handwerker richtet sich die von Dr. Karl Lueger geführte Kampagne, der den Wirtschaftsliberalismus mit dem Judentum und den Juden identifizierte

In Großstadtjuden beschäftigt sich der Autor mit denselben Erscheinungen, jedoch aus einem streng jüdischen Blickwinkel, der ausgeht von einigen Familien und der Art, wie jede von ihnen auf den wachsenden Antisemitismus in 
der österreichischen Hauptstadt reagiert. Im Rückblick stellt sich die Geschichte der österreichischen Juden, zu jener Zeit die nach Warschau zweitgrößte Gemeinde in Europa, in diesem Roman als ein Vorspiel der Geschichte der Juden Europas im 20. Jahrhundert dar, was diesem literarischen Werk, das zum Vergessen verurteilt schien, ein unerwartetes Interesse verschafft.

Stichwörter: Habsburger Monarchie; Jüdisch-östereichische Symbiose; Assimilation; Antisemitismus; Jüdische Emanzipation.

Resumo: Este artigo trata do escritor austríaco Adolf Dessauer (1849-1916), um cronista de costumes da Viena da passagem do século 19 para o século 20. Banqueiro de profissão e escritor amador, Dessauer publicou em vida dois romances (Götz̧endienst, de 1896, e Großstadtjuden, de 1910) que são ambientados na metrópole habsburga, à época em rápida transformação econômica e social, e que hoje foram virtualmente esquecidos. Dessauer volta sua atenção para a classe social que ascendeu com o triunfo do liberalismo econômico, e que passou a relacionar-se, de maneira cada vez mais próxima, com a aristocracia decadente da capital austríaca, da qual mimetizava os gostos e os hábitos. Ao contrário do que aconteceria em outras nações européias, a burguesia, no Império Habsburgo, não criou um repertório cultural ou estético próprio, mas tentou apropriar-se, por meio da mímese, dos padrões culturais aristocráticos, o que gerou uma classe de imitadores sobre a qual Dessauer volta um olhar irônico e penetrante.

Ao mesmo tempo, Dessauer mostra como o partido dos cristãos anti-semitas, na Áustria, recrutou seu eleitorado dentre a camada de artesãos que, com o surgimento da nova ordem econômica, proletarizou-se: a estes artesãos empobrecidos dirigia-se a campanha promovida pelo Dr. Karl Lueger, que identificava com o judaísmo e com os judeus o capitalismo liberal.

Já em Großstadtjuden o autor volta-se sobre os mesmos fenômenos, porém de um ponto de vista estritamente judaico, que tem como ponto de partida algumas famílias e a maneira como cada uma delas reage ao crescente anti-semitismo na capital austríaca. Olhando-se em retrospecto, a história da comunidade judaica viensense, que à época de Dessauer era a segunda em tamanho na Europa, superada apenas pela de Varsóvia, afigura-se, neste romance, como um prelúdio de toda a história judaica na Europa do século 20, o que traz um inesperado interesse por uma obra literária que parecia condenada ao esquecimento. 
Palavras-chave: Monarquia habsburga; Simbiose austro-judaica; Assimilação; Anti-semitismo; Emancipação judaica.

O escritor vienense Adolf Dessauer (1849-1916) - que também era banqueiro - é hoje um autor praticamente desconhecido, exceto por uns poucos especialistas em literatura do Império Austro-Húngaro. Seu nome não aparece em nenhum dos dicionários especializados que tratam de literatura judaica em língua alemã, tampouco na maior parte dos livros de referência sobre a literatura austríaca.

Em vida, porém, Dessauer foi um escritor bastante conhecido e bem sucedido. Seu romance de estréia, de 1896, Götrendienst, (Reverência aos Ídolos), foi discutido num artigo de 180 linhas na Neue Freie Presse, o mais conceituado jornal vienense de seu tempo, ao mesmo tempo em que era duramente criticado por Karl Kraus em seu implacável jornal Die Fackel: para Kraus, o estilo de Dessauer "oscilava de acordo com as variações da bolsa de mercadorias."

Dessauer cresceu na época do triunfo do liberalismo político e econômico no Império Austro-Húngaro, e conviveu com o declínio da velha ordem imperial e a introdução de uma nova mentalidade tanto no universo judaico quanto nas estruturas sociais e culturais da monarquia habsburga. Conviveu, também, com o espantoso crescimento da comunidade judaica vienense, que na virada do século tornara-se a segunda mais importante em tamanho na Europa - e provavelmente a mais relevante do ponto de vista da criatividade cultural e do poderio econômico.

Se o fim do século 19 em Viena foi uma época de rápidas transformações nas referências culturais e religiosas para os judeus recém-chegados das mais diversas províncias do Império, este período representou, também, o apogeu de um esforço de assimilação dos judeus austríacos às culturas cristã aristocrática e secular burguesa, que conviviam e se interpenetravam na capital imperial.

Independentemente das qualidades estéticas de seus romances, hoje considerados pelos poucos especialistas que os conhecem como "romances de entretenimento", Dessauer traçou um retrato agudo, preciso bem- 
humorado da vida social vienense, num idioma ágil e de leitura sempre atraente e cativante. Por sua posição social, supostamente Dessauer era freqüentador dos teatros, bailes e salons da elite vienense retratados em sua obra de ficção, sempre com um olhar crítico e penetrante. O ponto de vista de Dessauer para retratar e julgar seus contemporâneos é sempre o de uma ética familiar e social sólida, indubitavelmente tributária da tradição judaica, e solidamente assentada nos princípios de um patriciado judaico que se vê como parte e como herdeiro da rigidez moral habsburga. Arqui-conservador, ancorado em sua posição social tanto quanto nos fundamentos éticos do judaísmo e da dupla monarquia, Dessauer olha sempre com fina ironia para o desvairio de seus contemporâneos. Seus personagens, a quem falta, justamente, a solidez moral, social e econômica do patriciado, da qual Dessauer, sem dizê-lo, se coloca como representante, estão em busca permanente e incansável dos prazeres mundanos. Suas vidas se esgotam no hedonismo e no esteticismo levado ao paroxismo, característicos da cultura vienense da virada do século, ao mesmo tempo em que sua obsessão pelas aparências da vida aristocrática os leva a uma mimetização de suas formas que não leva em conta seu conteúdo, e que não raro degenera em puro voyeurisme.

Essa sede pela adoção das formas de vida aristocráticas está ligada ao fato de que, ao contrário do que aconteceria em outros países da Europa, a burguesia ascendente do Império Austro-Húngaro triunfou no âmbito econômico, porém não acompanhou este triunfo com a adoção de uma ideologia, de uma política ou de uma estética próprias. As formas sacrossantas de um império milenar pareciam-lhe irrepreensíveis e o culto ao Kaiser Franz Joseph como sinônimo do bom tom. As velhas formas, assim, eram mimetizadas para que os recém-chegados se sentissem membros da velha ordem, que não pretendiam derrubar, mas à qual gostariam de assimilar-se. $\mathrm{O}$ burguês de origem judaica, chamado Karpeles, que quer se fazer passar por um descendente de incontáveis gerações se senhores feudais, e adota o nome de Richelieu é, assim, uma das figuras aberrantes e grotescas - e ao mesmo tempo emblemáticas - que Dessauer retrata em Großstadjuden, (Judeus da cidade grande), seu segundo e mais conhecido romance, de 1910:

A família (Richelieu) era originária de Praga, de onde se mudara para Viena havia apenas uns poucos anos. Em Praga Herr Karpeles tor- 
nara-se um homem rico, graças à conjuntura que fez prosperar enormemente seu negócio de madeiras, de início pequeno. Ele então vendeu o empreendimento, tomou para si o nome de Richelieu e mudou-se para Viena. Aqui, todo seu esforço concentrava-se em conquistar para si um nome como soberano na arte de viver e como desfrutador dos prazeres da vida, em estilo aristocrático. Ele participava de caçadas, apostava grandes quantias nos clubes e tinha uma amante assumida. $\mathrm{O}$ aspecto determinante de sua personalidade era uma vaidade sem limites, e ao mesmo tempo ingênua e infantil. Ele queria, a qualquer preço, ser admirado como um verdadeiro aristocrata. Suas paixões e prazeres exagerados the proporcionavam muito mais prazer por serem notadas e comentadas pelos outros do que por seu conteúdo intrínseco. (Dessauer 1910: 35) ${ }^{1}$

Se em Großstadtjuden Dessauer se volta, como se pode depreender do título, diretamente aos judeus da capital, seu romance de estréia, Götzendienst, tem como assunto principal a febre de mimetização que toma conta da sociedade vienense como um todo à sua época, febre esta que se volta para o teatro não como simples fonte de entretenimento, mas como lugar onde determinados padrões, idéias, atitudes e tipos de comportamento - além de palavras, trajes e gestos - podem ser aprendidos para serem aplicados na vida real. A teatralização da vida burguesa vienense, contaminada pela febre da mimetização, é, assim, vista como uma via de acesso à ordem na qual se deseja ingressar. Neste sentido, o teatro se torna o paradigma que fornece o repertório necessário a esta assimilação. É dele que se copia, um pouco à maneira do que se passa com as telenovelas brasileiras, os desejos e as aspirações; os jeitos de ser e de amar; a maneira de realizar festas e outros acontecimentos sociais:

Neste ponto as pessoas hoje são muito exigentes. Hoje em dia querse ver tudo em original no palco, em especial certas cenas de amor, que devem ser extraídas, ponto por ponto, da vida real. Afinal, há muita gente que vai ao teatro exclusivamente porque ali quer aprender algo de novo em suas relações [...] (DEssauer 1896: 33)

\footnotetext{
${ }^{1}$ A tradução das citações de Dessauer é minha (L.S.K.).
} 
A ânsia de mimetização faz dos atores de teatro os ídolos a que Dessauer se refere no título do livro, porém há outros ídolos que vão surgindo com o desenrolar da narrativa. Um deles é o Barão Frankenstein, talentoso financista de origem burguesa, que recebeu o título de nobreza em troca dos bons negócios que fez para o Estado, e cujo nome alusivo ao macabro personagem do romance de Mary Shelley, de 1818, não é acaso:

Frankenstein era membro da câmara alta, membro do conselho de administração das cinco principais sociedades anônimas e curador de um grande número de instituições humanitárias. Além disto, ele tinha seu próprio banco, grande e com muitas filiais, para dirigir um banco que estava em constante expansão e, como todos garantiam, tinha resultados comerciais totalmente extraordinários. O Barão já era considerado hoje como um dos homens mais ricos da cidade ... A posição social de Frankenstein era hoje a mais brilhante que se possa imaginar. Ele desfrutava da fama de ser um dos homens mais significativos e ao mesmo tempo mais bondosos de seu tempo. Em seu círculo mais íntimo, ele era diretamente comparado a um Deus. (Dessauer 1896: 97)

Frankenstein, com suas ambições ilimitadas e sua complexidade cada vez maior de atividades e compromissos, é um emblema do grande burguês que triunfa com a nova ordem liberal ao mesmo tempo em que anseia pelos signos e distinções da aristocracia. A pletora aparentemente irreconciliável de seus atributos e responsabilidades, que corresponde à ironia implícita em seu nome, é também representativa da avidez fáustica da camada burguesa emergente - avidez esta cujo resultado é caótico e desprovido de harmonia, um verdadeiro Frankenstein.

A idolatria criadora de Frankensteins, que por sua vez se tornam, eles mesmos, ídolos, passa, igualmente, pelo voyuerisme: um grupo de aristocratas que jantam no mais elegante restaurante do Prater, o grande parque de diversões vienense, proporcionam um inesperado espetáculo teatral ao ar livre, que proporciona aos passantes um deleite que faz pensar no cinema e na televisão:

"E o que dizer quando as pessoas se deleitam em observar seus semelhantes comendo? Eu acabo de passar diante do restaurante fran- 
cês. E lá estão as pessoas, das quais, inclusive, muitas parecem pertencer às chamadas classes educadas, amontoadas, com os olhares fixos nos poucos aristocratas e nos poucos burgueses que gastam mais dinheiro do que a média, enquanto eles desfrutam de seus saborosos jantares. E eles, é claro, sentem-se como os deuses do Olimpo que, desfrutando do néctar e da ambrosia, estão sentados em seus tronos, muito acima dos mortais que os admiram." (DEsSAUER 1896: 247)

Os personagens descritos por Dessauer são extraídos ou inspirados em personagens de seu convívio, e o Zeitgeist vienense do fim do século é a matéria principal de seus escritos. Se os cacoetes e ambições da classe emergente, bem como sua obsessão imitatória, são o assunto central de Götz̧endienst um tema secundário do romance, cujos personagens (ainda) não são declaradamente judeus, é a eleição de um representante do partido anti-semita para a câmara municipal. Representado no livro de Dessauer como o torneiro Burger, este representante guarda semelhanças com o primeiro candidato do partido anti-semita eleito para a câmara municipal vienense, o também torneiro Eulenberg, do distrito de Mariahilf, eleito em 1885.

Tanto o personagem de Dessauer quanto o vereador Eulenberg vivem em distritos distantes da capital e são membros de uma classe social empobrecida, que perdera seus privilégios com a introdução de novos meios de produção, com a ascensão do liberalismo e com as radicais mudanças que se processaram em Viena a partir do final do século 19.

Eles são os novos proletários, dentre os quais o partido anti-semita, criado em 1882, recrutava seus eleitores e a quem Karl Lueger, o chefe deste partido, que em 1896 se tornaria prefeito de Viena, dirigia seus vitupérios.

Eulenberg, tanto quanto Lueger, e da mesma forma que o vereador Burger concebido por Dessauer, utilizam o anti-semitismo como uma bandeira política, destinada a aglutinar seus eleitores, revoltados com a deterioração de sua posição social, em torno de uma nova bandeira. Os judeus eram associados, nos seus discursos, à expansão capitalista e ao liberalismo, no bordão, repetido ad nauseam, de Lueger, que falava em "luta incessante 
contra o grande capital internacional, organizado com a ajuda da expansão do judaísmo".

$\mathrm{Na}$ realidade, o afluxo de judeus à capital da monarquia austro-húngara e a expansão de um capitalismo de molde liberal que haveria de transformar não só as feições da cidade como sua estrutura social e, sobretudo, sua cultura, foram fenômenos concomitantes, porém não ligados por uma relação de causa e conseqüência. Os judeus que iam da província para a capital faziam-no, justamente, no afã de conquistar melhores condições de vida, e não como capitalistas já estabelecidos em busca de expansão para suas riquezas, embora já existisse uma diminuta parcela judaica na elite financeira da cidade desde meados do século 19.

Ao mesmo tempo, os judeus como um todo acabaram prosperando mais rapidamente do que a maioria da população, o que gerava os ressentimentos sobre os quais Lueger e seu partido construíram seu capital eleitoral.

O fluxo constante que trazia à capital os judeus das províncias, onde de início se dedicavam preferencialmente ao comércio, provocou uma situação de concorrência aos pequenos comerciantes e pequenos fabricantes e artesãos locais, de maneira que a origem do movimento anti-semita vienense do século 19 recrutou seu apoio político nesta camada numericamente importante.

Lueger conquistou a prefeitura da capital graças a um discurso cristão e socializante, que identificava os judeus com o liberalismo, e os apresentava como perseguidores do povo cristão e alemão. Assim, todos os grupos que se viam em situação de desvantagem ante os novos tempos se reuniram num novo partido político, denominado "Partei der antisemitischen Christen" - o partido daquele grupo extremamente numeroso, que foi prejudicado diretamente pelas novas formas da produção, e cujas tradições foram minadas pela introdução das máquinas e do liberalismo econômico.

Não se suspeitava que o recém-criado termo "anti-semita" viria a tornar-se uma das categorias centrais da praxis e da teoria políticas da Europa no século que estava por nascer. Mas a Viena da virada do século contribuiu de maneira extraordinária para o vocabulário da reflexão humanística e judaica do novo século. Além de anti-semitismo, surgiram ali termos como sionismo, assimilação, complexos e outros. 
O anti-semitismo de Lueger dirigia-se não especificamente aos judeus per se, mas a todas as transformações por que passava Viena, das quais os judeus se tornaram, em seus discursos, um símbolo e um emblema. Aos judeus atribuía-se a culpa por tudo o que foi destruído pelo liberalismo.

Em 1885, o primeiro candidato anti-semita à câmara municipal, o torneiro Eulenberg, foi eleito. Dez anos mais tarde, 74 liberais defrontavam-se com 64 anti-semitas nessa casa, e no fim de 1895 havia, ali, 91 antisemitas ante 46 liberais. Na câmara estadual, os anti-semitas também haviam se tornado a maioria e no parlamento já eram uma força decisiva. A oposição do alto clero aos anti-semitas, bem como dos arqui-conservadores, tornou-se insustentável e em 1896 o imperador Franz Joseph foi obrigado a conceder a prefeitura da cidade a Karl Lueger.

$\mathrm{O}$ anti-semitismo de Lueger, porém, tinha clara para ele mesmo sua motivação. Embora vituperasse contra os judeus, Lueger em diversas ocasiões honrou, no parlamento, o judeu Adolf Fischhof, declarando ser ele um homem de estatura moralmente superior à de qualquer outro membro daquela casa. Além disto, Lueger tinha, como todo bom anti-semita de sua época, amigos judeus. Em Götzendienst Dessauer faz referência à ambivalência do anti-semitismo promovido pelo partido:

Agora, porém ocorreu a Burger que o homem com quem ele conversava era judeu. "Não me leve a mal, Doutor," desculpou-se ele. "É claro que nada disto se refere ao senhor - o senhor bem sabe - e sobretudo, o Reiblinger e os outros dirigentes dizem: não temos nada contra o judeu individualmente, nós só combatemos os judeus - o senhor entendeu a diferença?"

"Não exatamente," respondeu Roth, irônico. "Me parece que os judeus consistem de muitos judeus individualmente..." (Dessauer 1896: 172)

A atitude de Lueger, assim como as ambivalências de alguns de seus seguidores, está de acordo com a bonomia hipócrita, parte do folclore que se criou em torno da atmosfera austríaca à época do declínio do império, e as contradições desta bonomia estão em linha com as contradições de uma classe social emergente, que busca apenas herdar as formas e as aparências da classe que está em vias de desaparecimento, sem preocupar-se com seus 
conteúdos. A superficialidade deste anti-semitismo, que é uma espécie de moda, resume-se na seguinte frase de Burger:

"Eu já expliquei a ele que os senhores não querem ofendê-lo, porque eles gostam muito do judeu individualmente, e só não suportam os judeus..." (Dessauer 1896: 174)

A perseguição aos judeus em Viena começou como um movimento popular, destinado a defender os interesses de pequenos comerciantes e artesãos contra a população judaica que, no rastro do édito de tolerância de 1872, começou a chegar, em quantidades crescentes, das províncias do Império Austro-Húngaro. Embora houvesse uma população judaica em Viena desde 1848, e até mesmo uma diminuta aristocracia judaica, da qual eram membros, entre outros, os barões Rothschild e Hirsch, os judeus representavam pouco mais de $2 \%$ da população da capital habsburga antes de 1860 , quando havia em Viena apenas 6.200 judeus. Em 1870, eles já eram 40.200, ou 6,6\% e em 1880 eram 72.600 ou 10,1\%. (cf. TIETZE 1933: 203). Em 1890 eram 118.500, mas que representavam agora só 8,7\% da população da cidade, cujo número de habitantes duplicara. Em 1900 eram 147.000, ou 8\%; em 1910 175.300, ou 8,6\%.

Em Viena, assim, surgiu a segunda maior comunidade judaica da Europa, depois de Varsóvia e, como convinha à capital de um império milenar em cujo território se misturavam oito nacionalidades e mais de uma dezena de idiomas, era uma comunidade extremamente diversificada e multifacetada. Das moradias pobres dos judeus ultra-ortodoxos, recémchegados do Shtetl (aldeia judaica do Leste europeu), situadas na Leopoldstadt ou $2^{\circ}$ distrito, até os cafés freqüentados por boêmios e artistas; dos salões da burguesia esclarecida até o consultório do Dr. Freud, um vasto espectro de visões de mundo, princípios éticos e aspirações estavam representados entre os judeus de Viena.

A heterogeneidade da comunidade judaica vienense levou, inclusive, à formação de diferentes comunidades em seu interior, que se olhavam, umas às outras, com o mesmo grau de estranhamento, quando não de desdém, com que viam os outros grupos étnicos e sociais da cidade. E havia, até mesmo, um respaldo teórico para este estranhamento, que chama a 
atenção, também, para uma outra questão: a das nacionalidades dentro do império habsburgo.

Oficialmente, as nações habsburgas eram a alemã, a tcheca, a polonesa, a eslovena, a italiana, a romena e a rutena (ucraniana), além da húngara. No entender de Sigmund Mayer, um dos historiadores do judaísmo vienense - e de muitos de seus contemporâneos - os judeus nascidos em meio a cada uma destas nacionalidades a ela pertenciam, em função de seu idioma e de sua formação cultural: “os judeus evidentemente pertencem àquela nação com a qual partilham de um solo comum, uma língua, uma cultura e à qual se vêem ligados por interesses políticos, materiais, e econômicos. Ao mesmo tempo, eles também têm a capacidade de sentirem-se como judeus." (MAYER, 1917, p. 484)

O judeu per se é, neste quadro, uma ficção criada pelo imaginário antisemita, e não uma realidade social. Se havia, em Viena, o judeu tcheco e o judeu húngaro, o judeu galiciano e o judeu italiano, o judeu esloveno e o judeu sérvio, além do judeu vienense, era impossível encontrar, entre os judeus de Viena, qualquer denominador comum que não sua origem étnico-religiosa.

Se esta circunstância terminaria por invalidar, aos olhos do eleitorado, os vitupérios do Dr. Karl Lueger, ela explica, também, o surgimento de um novo anti-semitismo, de base racial, igualmente surgido em Viena, e de onde se propagaria para tornar-se a base da ideologia nazista, este sim capaz de reduzir a um bloco único aquilo que naturalmente era tão multifacetado, resistente aos conceitos e incompreensível.

Assim, ao velho anti-semitismo de Lueger, que, segundo ele mesmo, não se dirigia aos judeus individualmente, mas apenas contra os "judeus", numa formulação característica da Gemütlichkeit vienense, surge, com a chegada do século 20, outro, mais implacável, com uma suposta base "científica". Assim, se o lar judaico vienense tem uma característica comum, esta é a preocupação com o anti-semitismo, que ao revestir-se de uma aura "científica", se torna cada vez menos suportável.

Se no primeiro romance de Dessauer, publicado em 1896, aparece um único e secundário personagem abertamente judeu, seu segundo (e mais conhecido) romance, de 1910, que leva o título de Großstadtjuden (Judeus da cidade grande), tem o anti-semitismo e a comunidade judaica como 
temas centrais. Praticamente contemporâneo é o romance de Arthur Schnitzler intitulado Der Weg ins Freie (O caminho para a liberdade), de 1908, que trata, igualmente, das relações entre judeus e cristãos, do antisemitismo e da identidade judaica em Viena.

Se o anti-semitismo de base racial é o responsável pela criação de uma comunidade judaica em bloco, que não existia até então em Viena, vistas as diferenças nas origens, na cultura e mesmo na etnia de suas múltiplas subdivisões, as reações a este fenômeno serão tão diversificadas quanto os seus membros. Há os que buscam a assimilação ao novo tempo, que no entanto mostra-se uma quimera de formas tão mutáveis quanto inapreensíveis, e que acaba por levar não poucos de seus adeptos aos consultórios dos psicanalistas quando não às muralhas do Steinhof, o colossal sanatório psiquiátrico no verdejante bairro de Hietzing, que pode ser visto como a contrapartida da erupção dos novos paradigmas culturais que surgem com o declínio de uma ordem imperial fundada na religiosidade e na tradição. Há um sem-número de homens e mulheres financeiramente independentes, que buscam no deleite e na sublimação da arte um refúgio para os paradoxos da realidade político-social. O deleite estético, assim, torna-se um dos pólos centrais da vida sócio-cultural da cidade, e atrai um número desproporcional de autores, atores, diletantes e aficcionados de origem judaica, que aí buscam um significado para suas existências e um conforto psíquico que já não mais encontram na vida social. Há os que buscam na conversão ao catolicismo um fim para o sentimento de rejeição que enfrentam em suas vidas quotidianas, ou um conforto espiritual que já não mais encontram na religião de seus antepassados. Há os que crêem no sionismo como solução para seus problemas e há os que estão convictos de que somente o socialismo, ou a ação do partido liberal, ou a ciência, serão a solução para o monstro do anti-semitismo que, não obstante a pletora de soluções, não pára de crescer em Viena, até atingir seu paroxismo com o Anschluss, em 1938, e os acontecimentos que se sucederam a ele. E há os que acreditam no patriotismo e na monarquia e em seu velho imperador como representantes de uma justiça divina e transcendente

Schnitzler tanto quanto Dessauer dedicam seus "romances judaicos" justamente a retratar a diversidade da comunidade judaica vienense e o fazem por meio da diversidade de suas reações a um anti-semitismo cada vez mais virulento e inescapável. 
O bloco judaico, assim, é algo que surge não a partir de um sentimento de solidariedade judaica per se, mas parece resultar do anti-semitismo racial que se torna cada vez mais virulento no século 20 , e ao qual estão associados o genocídio tanto quanto o surgimento do estado de Israel.

\section{Referências bibliográficas}

Broch, Hermann. "Hofmannsthal und seine Zeit" in Schriften zur Literatur. Frankfurt a. M., Suhrkamp 1975.

Dessauer, Adolf. Götzendienst. Leipzig, Reclam 1896.

Idem. Großstadtjuden. Viena, Wilhelm Braumüller 1910.

Herzog, Andreas. "Die Mischehe zur Lösung der Judenfrage - Adolf Dessauers Roman Großstadtjuden im soziokulturellen Kontext der Wiener Jahrhundertwende". In: Kakanien Revisited 11. 2003. 125.

Mayer, Sigmund. Die Wiener Juden - 1700 - 1900. Berlim e Viena, K. Löwit 1917.

Rozenblit, Marsha L. Die Juden Wiens 1867-1914 - Assimilation und Identität (trad. Karl Erwin Lichtenecker). Viena, Böhlau 1989.

Schorske, Carl. Fin-de-siècle Vienna-Politics and Culture. Nova York, Knopf 1980.

Tietze, Hans. Die Juden Wiens. Viena, Edition Atelier 1987. 